\title{
Supporting Teachers' Intervention in Students' Virtual Collaboration Using a Network Based Model
}

\author{
Tiffany Herder \\ University of Wisconsin - Madison \\ 1025 W Johnson Street \\ Madison, WI, US \\ therder@wisc.edu \\ Andreas Lindenskov Tamborg \\ Aalborg University \\ A. C. Meyers Vænge 15 \\ Copenhagen, Denmark \\ alt@learning.aau.dk \\ Morten Misfeldt \\ Aalborg University \\ A. C. Meyers Vænge 15 \\ Copenhagen, Denmark \\ misfeldt@learning.aau.dk
}

\author{
Zachari Swiecki \\ University of Wisconsin - Madison \\ 1025 W Johnson Street \\ Madison, WI, US \\ swiecki@wisc.edu \\ Benjamin Brink Allsopp \\ Aalborg University \\ A. C. Meyers Vænge 15 \\ Copenhagen, Denmark \\ ben@learning.aau.dk
}

\author{
Simon Skov Fougt \\ University College Metropol \\ Nyelandsvej 27-29 \\ Fredriksberg, Denmark \\ sifo@phmetropol.dk \\ David Williamson Shaffer \\ University of Wisconsin - Madison \\ 1025 W Johnson Street \\ Madison, WI, USA \\ dws@education.wisc.edu
}

\begin{abstract}
This paper reports a Design-Based Research project developing a tool (the Process Tab) that supports teachers' interventions with students in virtual internships. The tool uses a networked approach and allows insights into the discourse of groups and individuals based on contributions in chat fora and assignments.

In the paper, we present the tool and reports from interviews with three teachers who used the tool. The interviews provide insights about the teachers' hopes, actual use, and difficulties with the tool. The main insight is that even though the teachers genuinely liked the idea and specific representations of the Process Tab, their lack of ability to teach and look at the tool at the same time hindered their use. In the final part of the paper, we discuss how to address this issue.
\end{abstract}

\section{CCS CONCEPTS}

- Applied computing Computer-managed instruction • Applied computing Computer-assisted instruction

Permission to make digital or hard copies of all or part of this work for personal or classroom use is granted without fee provided that copies are not made or distributed for profit or commercial advantage and that copies bear this notice and the full citation on the first page. Copyrights for components of this work owned by others than the author(s) must be honored. Abstracting with credit is permitted. To copy otherwise, or republish, to post on servers or to redistribute to lists, requires prior specific permission and/or a fee. Request permissions from Permissions@acm.org.

$L A K^{\prime} 18$, March 7-9, 2018, Sydney, NSW, Australia

(c) 2018 Copyright is held by the owner/author(s). Publication rights licensed to $\mathrm{ACM}$.

ACM 978-1-4503-6400-3/18/03\$15.00

https://doi.org/10.1145/3170358.3170394

\section{KEYWORDS}

ACM proceedings; virtual collaboration; learning analytics; teacher practices; teacher intervention; immersive learning environments

\section{ACM Reference Format:}

T. Herder, Z. Swiecki, S. Skov Fougt, A. Lindenskov Tamborg, B. Brink Allsopp, D. Williamson Shaffer, and M. Misfeldt. 2018. Supporting teachers' interventions in students' virtual collaboration using a network based model. In LAK'18: International Conference on Learning Analytics and Knowledge, March 7-9, 2018, Sydney, NSW, Australia. ACM, New York, NY, USA, 5 pages. https://doi.org/10.1145/3170358.3170394

\section{INTRODUCTION}

Immersive learning environments create strong opportunities for learning [1-6]. The rich digital footprints students leave in such environments allow detailed analysis of their performance, interaction, and, hence, their learning $[\underline{7}, \underline{8}]$. However, for these environments to genuinely support existing educational practice, the extent to which teachers can use this knowledge is critical. This challenge of supporting teachers is acknowledged in the learning analytics community [9].

In the case of immersive learning environments, the challenge of learning analytics is difficult because of what we previously described as the paradox of pedagogical simulations [10]; the more complex, rich, and immersive a pedagogical simulation is, the more difficult it is for teachers to genuinely interact and intervene in students' learning process. This paradox manifests itself in a number of design problems for pedagogical software. For example, teachers encounter difficulty when they want to redesign an immersive learning environment [10] due to the 
technical skills needed and the number of internal dependencies. Another example is the problem of interpreting and understanding the students' ongoing learning process while they're immersed in a virtual universe.

In the case of virtual internships, Shaffer and colleagues developed a suite of theoretically grounded learning analytics tools that allow researchers to interpret and compare students' network of relations between critical concepts [11, $\underline{7}, \underline{12}, \underline{13}]$. These epistemic network analysis (ENA) tools allows us to obtain fine-grained images of student learning. However, the network graphs are hard to interpret and originally aimed at educational research. Hence, the research problem of this paper is to provide the critical insights of the epistemic network analysis in a form teachers can use in real time in the classroom. To address this design problem, we initiated a participatory Design-Based Research project [14] to develop the Process Tab, a tool that enables teachers to get these insights while simultaneously learning about the dimensions of presenting complex, actionable learning analytics to teachers. Technologies are often associated with the potential of making teachers' work easier and faster to do, but teachers' valuation of technologies are closely associated with its epistemic value [15]. Research found that teachers believe that often priority is given to the production of data rather than supporting student learning [16]. The purpose of developing the Process Tab was to produce and visualize data about collaborative student activities to support teacher interventions.

In this paper, we present the Process Tab and the participatory Design-Based Research process conducted so far. Further, we describe data collected and insights gained from the analysis of each iteration. Finally, we discuss critical dimensions and challenges for teachers use of learning analytics in immersive learning environments.

\section{VIRTUAL INTERNSHIPS AND TEACHING}

Virtual internships are simulated workplace environments where students work with complex, real-world STEM problems for which there is no optimal solution [17, 18]. For this study, the context in which teachers use the Process Tab is Land Science [19]. In Land Science, students assume the role of interns at an urban planning firm and develop a rezoning plan for the city of Lowell, Massachusetts. Students work in project teams to review research briefs, conduct stakeholder assessments, use a GIS mapping tool to model land-use changes (Figure 1), and write a formal proposal to convince stakeholders that the plan balances a variety of their concerns.

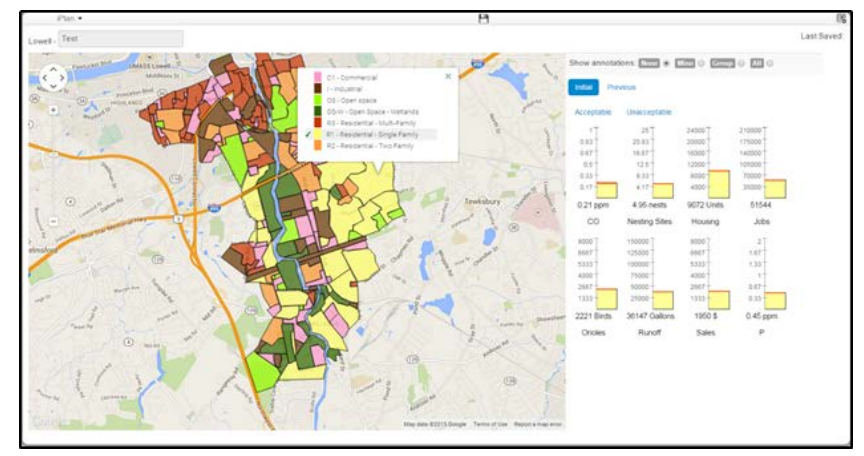

Figure 1: Land Science GIS Mapping Tool.

Throughout Land Science, students engage in discourse using the chat tool integrated into the virtual internship platform.

\section{THE PROCESS TAB}

To understand what teachers need to support students in virtual internships, we developed a tool that supports teachers' real time access to representation of the connections students make among various domain concepts within their discourse. The Process Tab, which is the focus of this paper, sits in a larger suite of views called the Teacher Interface which provides support for various administrative and pedagogical tasks.

We developed the Process Tab in response to feedback from our "Core Developer Network" (CDN). The CDN is a group of teachers who used the Virtual Internship Authoring Tool (VIA) to create their own versions of virtual internships [10]. Based on their input, we drafted a first round of designs. These designs were conceived of as an overlay on the existing virtual internship interface. They focused on showing key characteristics of group discussions-amount of participation by each student, overall quality, the quality of an individual's contributions to the group, the content-and deliverables submitted and curricular standards met by each student.

Concurrently, we developed predictive learning analytic models to drive the visual representations of discussion quality and contributions. We developed these models using the discourse network tool ENA. Epistemic Network Analysis operationalizes the associations present in discourse that a person makes between the skills, knowledge, identity, values, and epistemology of a given community of practice [11]. ENA collects in situ longitudinal data documenting the development of and linkages among these elements which comprise an epistemic frame. The predictive models within the Process Tab were developed using prior student data from the virtual internship and used the connections students make between epistemic frame elements to predict their performance on an outcome measure. The basic function of the models was to distinguish high performing students from low performing students based on the presence and number of connections made between these important domain concepts. As we refined these models, we redesigned the components of the Teacher Interface related to discussion quality and contributions to better fit the model. The result was a separate 
Supporting Teachers' Intervention in Students' Virtual Collaboration Using a Network Based Model

part of the Teacher Interface devoted to representing the discussion processes of groups and individual students named the Process Tab. This second round of designs better reflected the underlying ENA network models while simplifying the visuals, so teachers could more easily understand them. In addition to the Process Tab, we refined our gradebook designs and created additional tabs for viewing notebook submissions and assessments, curricular standards met, and high-level statistics about student and group behavior (Figure 2). We again presented this second iteration to teachers.

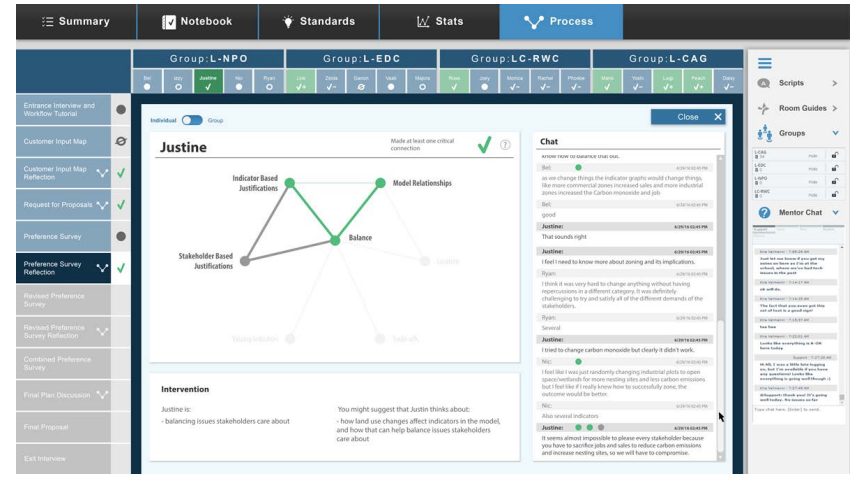

Figure 2: Second Round Design of the Process Tab.

After receiving feedback, we finalized our predictive learning analytic models and drafted a final round of designs. For the Process Tab, these designs included a high-level summary view of the quality of individual contributions to discussions, further simplified network models, a complete record of chats, and suggested interventions based on student discussion performance. Then, we completed a final round of teacher review. After final tweaking of the designs, we built the first version of the new Teacher Interface.

We then tested the interface with teachers and hypothesized use cases. We thought teachers would: (1) view students' networks to evaluate their performance, (2) use suggested interventions to support student performance, (3) use the summary icon to get a high-level overview of student performance, and (4) use the scroll back feature to review how students' networks built over time.

To develop a nuanced understanding of our hypotheses, we conducted an interview study and presented the initial results to teachers at a meeting in August 2017. Currently, we continue to gather data and feedback to improve the Teacher Interface.

\section{INTERVIEW STUDY}

To learn about the teachers' expectations and use of the Process Tab, we conducted semi-structured interviews with three teachers who used the tool since its initial launch in Fall 2016. Teachers were selected based on clickstream data that indicated they used the interface during their implementation of the virtual internship. We recruited the participants through our contacts at the Massachusetts Audubon Society and our Core Developer
LAK'18, March 7-9, 2018, Sydney, NSW, Australia

Network. All three participants work in formal education settings with high school students. The interview questions included: What were you hoping the Process Tab could provide to you? Could you describe for me how you used this network diagram? How did your actual experience with the Process Tab differ from your original hopes for using it?

We coded the interview transcripts turn-by-turn using a codebook focusing on how the Process Tab, Teacher Interface, and Virtual Internship (1) supported teachers' and students' work, (2) challenged and constrained teachers' and students' work, and (3) how the Process Tab was actually used by the teacher in relation to our four hypotheses. We also coded for suggestions and expectations related to the tool. The Process Tab and Teacher Interface codes focused on actual use, features that supported or hindered teachers' practices within the classroom, and suggestions for improving aspects of the tool such as different layouts or new features. The constraint codes differentiated three aspects of the teachers' experience that affected their ability to use the tool successfully within their classroom. These aspects included student characteristics such as ability, affect, or behavior, aspects of the virtual internship such as meeting question design or instructions, and teachers' own limitations such as a lack of time or proficiency with the tool.

\section{RESULTS}

The results related to the Teacher Interface were positive since the teachers valued the possibilities for supporting students work, following their progress, and encouraging them when they reached their goals. But they also pointed to a number of constraints and areas of improvements relating to the user interface and the representations. The three teachers agreed, however, of the promise related to the aggregation of data about students' learning.

Focusing on the teachers' experience with the Process Tab, two issues were clearly present: (1) The teachers expressed promise and hope in the Process Tab, but (2) they never really used it. In the following analysis, we aim to understand why. When describing our data we refer to the teachers as T1, T2, and T3 followed by an utterance id.

All three teachers valued the individual and group network representations to support their ambition of assessing students' higher order thinking ( $\mathrm{T} 1$ 46). This finding aligned with hypothesis one that teachers would view students' networks to evaluate performance. In a sense, the network comes closer to assessing what the teacher actually cared about, in contrast with a classical scoreboard (T1 36): "[usually and] especially in the sciences. It gets very chopped up into individual concepts."

The teachers did not have broad experience with such higher order assessment. However, the teachers did attempt to use the summary icons within the Process Tab, as we imagined with hypothesis three, to help them choose where to direct their attention in class (T3 289): "[Using the system] was a good quick way for me to go "Okay, I need to go after these kids and try and prompt them to do stuff." 
The system did not, however, provide assessment that was reliable enough for the teachers to use it without further thinking (T2 129): "So I'm using [the Process Tab] after the fact. I'm going back in there afterwards and I'm going through each conversation to look for quality and then I'm going to the Process Tab to say, "What was the computer saying." So, when I went to the gradebook and I saw open circles versus closed circles versus check marks or whatever. I couldn't even use that as a baseline because I'd have like one check mark". Hence, T2 experienced that the assessment from the Process Tab was not accurate enough, and she used a lot of cognitive energy and time going back to understand the tool's assessment, which challenges the value of the tool. It also showed that although the teacher viewed the network diagram and valued the representation, the use of the network for evaluating students' performance was more limited than we expected with hypothesis one. This teacher also expressed that even though she was using the Process Tab after class, due to the inaccuracy of the networks, she did not scroll back in chat as we expected in hypothesis four. She said she valued the idea of the function, however (T2 163).

The three teachers also found that their ambition to use the tool while teaching was very hard to fulfill because it was difficult to find time and energy (T2 129): "During the class where the meetings were happening, I didn't have a chance to use it, and that's because you're, as the teacher, you're, somebody is having a computer problem, somebody is coming in late, somebody wants to show you a homework they've done."

The three teachers had difficulties combining work in the Process Tab with face-to-face presence with their students. This problem was described as lack of time when they needed to both participate with their students and monitor their process to an extent that the information provided by the tool could be helpful (T1 50): "Logistically, in the middle of my classes, I was only able to go back to that screen intermittently. There was, I was doing a lot more running around the room supporting the kids than was ideal, but that was one of the ways of keeping them engaged."So, the focus on supporting students and ensuring their motivation was taking all T1's time and hindering the use of the tool.

The difficulties concentrating on the tool was also expressed by the teachers as not being able to "be in the moment" (T2 171): "I wasn't looking at it [during class]. You know, you're just troubleshooting. You're never, I feel like I'm never in the moment. Yeah or I am, I am rarely in the moment”, or, simply, as a lack of time for looking at the tool (T3 233).

Despite these difficulties, however, one teacher used the Process Tab to motivate and engage students. T3 used the summary icons during the virtual internship to keep her students on task and engaged as we imagined in hypothesis three (T3 245): "I was trying to be on them, constantly. Whoever it was...I would look and be like "okay, open circle" and it's like "Hey fose, be on task. It doesn't sound like you're doing anything relevant." She also used the interventions, as we imagined in hypothesis two, to interact with her students (T3 247): "[the student] would be like, "oh, ok, so you mean I have to talk about each stakeholder?” and I'm like, "Yeah, maybe the relationship between how you balance all of this."

Overall, all three teachers were very positive about the idea of the network diagrams, but they had very different experiences actually using them. T1 did not have many students whose performance was at the level where a strong network emerged, however, she used the network representations for those few students to praise their performance and prompt them to share their insights with group members (T1 28): "I definitely used that as an opportunity to pat them on the back for getting what Kira was trying to get across to them. For learning the material enough to apply it and invited them to share what they have learned with the other students on the team". T1 also discussed how the networks helped her think about her students' complex thinking and determine additional activities to prompt further development (T1 38): "I'm going more in the direction of synthesis... [the networks] really helped me develop the next set of tools that I developed for the students in order to get them to buy back in".

For T2, the network representations were not accurately reflecting her students. She felt that the Process Tab was not recognizing domain concepts in her students' contributions. She also felt that when a student makes an affirmation like "I agree," they should be viewed as substantial contributions and be given credit (T2 135): "So, if they say "yes, I agree" or "yes, I think you're right," the program was not saying that they were making a connection." She thought the idea of the network was valuable, however, and hoped she would be able to use it with her class (T2 119): "I think the idea of [the Process Tab] is really interesting, right, especially with the web effect... The idea is those are all the things and the points that I want them to be talking about."

Finally, T3 had difficulties interpreting the networks, so she did not use them for assessment in her class (T3 337): "I thought it was a great facilitation tool. I don't know about as an assessment tool. Especially now after going back through like "Check minus. Why is it a check minus?" I don't think that the way it is right now is very helpful in terms of judging whether something was a check plus or a check minus." She felt the network diagrams were important for getting to the whole purpose of the internship, however, and wished there were Process Tabs for "everything" (T3 356): "I think it's actually very important because you can have somebody who is giving everybody lip service, not actually thinking at all or demonstrating that they're thinking at all ... I think that's the whole point of this internship, to come up with ideas and communicate them to others and actually discuss stuff. I actually wish that there were Process Tabs for everything... Not just the discussion rooms, but for the whole internship."

In summary, the teachers liked the idea of the Process Tab and our hypothesized use cases with some minor reservations. But despite the fact that they liked the ideas of the network diagrams, suggested interventions, summary icons, and scroll back feature, they did not really use the tool. The analysis offers the reason for this as related to teachers' practical ability to be present in the class while spending time reading and interpreting the representations in the Process Tab.

In the final section, we discuss how to overcome this issue and what it means for the possibilities and difficulties in designing learning analytics applications directed towards teachers. 


\section{DISCUSSION AND CONCLUSION}

The interviews provide us with a possible way forward for learning analytics that, like the Process Tab, aim at overcoming the paradox that started our investigation-the more complex, rich, and immersive a learning environment is, the more difficult it is for teachers to interact with students.

If we want our learning analytics to genuinely support a digitalization of the mainstream, we are faced with the challenge of understanding teachers' work situation. In the case presented here, it is easy to understand why the three teachers never really used the tool even though they felt it could enable them to support students' higher order thinking, facilitate group collaboration, and provide targeted interventions. If you must be present in a classroom of students with various needs, then it is hard to find time to interpret abstract representations of their conceptual development.

Lack of time and the need to evaluate and interpret presented information, therefore, hinder strong adoption of learning analytics by teachers. Together, the combination of the two issues make everything worse. The teacher simply does not have the time to check and reflect upon the system output. This aligns with what we know about teachers' adoption of digital tools. A major concern is the sparse time and support available for learning the tools and incorporating them in daily professional work [20]. The insights from this interview study provide a potential clarification of this issue. The double presence experienced by the teachers illustrates that integrating tools like the Process Tab in teaching is difficult and that new teaching practices must be developed.

For learning analytics to genuinely support teachers during students' engagement in pedagogical simulations, we need strategies to balance teachers' need to interpret information about their students with their limits on attention. Interpreting information and overcoming disagreement with the tool requires cognitive energy. But the more energy teachers use on the tool, the more torn they will be between being present in the classroom and processing data from the tool.

This problem may be increased when using complex and abstract models, as we do in the Process Tab, however the advantage of such models is that they maintain some of the complexity of students' learning and do not reduce them to numbers. Hence, the double presence requires teachers to handle a paradox of teaching with learning analytics-the more complex and rich information about students' learning is presented, the more difficult it is for teachers to use that information while genuinely being present in the classroom and interacting with and intervening in the students' learning process.

\section{ACKNOWLEDGMENTS}

This work was funded in part by the National Science Foundation (DRL-0918409, DRL-0946372, DRL-1247262, DRL-1418288, DRL1661036, DRL-1713110, DUE-0919347, DUE-1225885, EEC1232656, EEC-1340402, REC-0347000), the MacArthur Foundation, the Spencer Foundation, the Wisconsin Alumni Research Foundation, and the Office of the Vice Chancellor for Research and Graduate Education at the University of Wisconsin-Madison.
The opinions, findings, and conclusions do not reflect the views of the funding agencies, cooperating institutions, or other individuals.

\section{REFERENCES}

[1] D.B. Clark, B. Nelson, P. Sengupta, \& C.M. D’Angelo. 2009. Rethinking science learning through digital games and simulations: Genres, examples, and evidence. Proceedings of the National Academies Board on Science Education Workshop on Learning Science: Computer Games, Simulations, and Education. Washington D.C.: National Academies Press.

[2] M.J. Dondlinger. 2007. Educational video game design: A review of the literature. Journal of Applied Educational Technology, 4, 1, 21-31.

[3] M.A. Honey, \& M.L. Hilton (Eds.). 2011. Learning science through computer games and simulations. National Academies Press, Washington D.C.

[4] K. Squire. 2011. Video Games and Learning: Teaching and Participatory Culture in the Digital Age. Technology, Education--Connections (the TEC Series). Teachers College Press, New York, NY.

[5] J.J. Vogel, D.S. Vogel, J. Cannon-Bowers, C.A. Bowers, K. Muse, \& M. Wright. 2006. Computer gaming and interactive simulations for learning: A metaanalysis. Journal of Educational Computing Research, 34, 3, 229-243.

[6] K.A. Wilson, W.L. Bedwell, E.H. Lazzara, E. Salas, C.S. Burke, J.L. Estock, K.L. Orvis, \& C. Conkey. 2009. Relationships between game attributes and learning outcomes: Review and research proposals. Simulation \& Gaming, 40, 2, $217-$ 266

[7] D.W. Shaffer. 2017. Quantitative ethnography. Cathcart Press, Madison, WI

[8] V.J. Shute. 2011. Stealth assessment in computer-based games to support learning. Computer games and instruction, 55, 2, 503-524

[9] K. Holstein, B.M. McLaren, \& V. Aleven. 2017. Intelligent tutors as teachers' aides: exploring teacher needs for real-time analytics in blended classrooms. In Proceedings of the Seventh International Learning Analytics \& Knowledge Conference (pp. 257-266). Vancouver, British Columbia: ACM.

[10] Z. Swiecki, M. Misfeldt, J. Stoddard, D.W. Shaffer. 2017. Dependency-Centered Design as an Approach to Pedagogical Authoring. In Y. Baek (Ed.), GameBased Learning: Theory Strategies and Performance Outcomes. NOVA, Hauppauge, NY.

[11] D.W. Shaffer, D. Hatfield, G. Svarovsky, P. Nash, A. Nulty, E. Bagley, K. Frank, A. Rupp, \& R. Mislevy. 2009. Epistemic Network Analysis: A prototype for 21 st century assessment of learning. International Journal of Learning and Media, 1, 2, 33-53.

[12] D.W. Shaffer, \& A.R. Ruis. 2017. Epistemic network analysis: A worked example of theory-based learning analytics. In C. Lang, G. Siemens, A. Wise, \& D. Grasevic (Eds.), Handbook of Learning Analytics (pp. 175-187). Society for Learning Analytics Research.

[13] D.W. Shaffer, W. Collier, \& A.R. Ruis. 2016. A tutorial on epistemic network analysis: Analyzing the structure of connections in cognitive, social, and interaction data. Journal of Learning Analytics, 3, 3, 9-45.

[14] S. Barab, \& K. Squire. 2004. Design-based research: Putting a stake in the ground. Journal of the Learning Sciences, 13,1, 1-14.

[15] J.D.M. Underwood, \& J. Stiller. 2014. Does knowing lead to doing in the case of learning platforms? Teachers and Teaching, 20, 2, 229-246.

[16] N.Selwyn. 2011. 'It's all about standardisation' - exploring the digita (re)configuration of school management and administration. Cambridge Journal of Education, 41, 4, 473.

[17] N. Chesler, W. Collier, Z. Swiecki, G. Arastoopour, \& D.W. Shaffer. 2015. A novel paradigm for engineering education: Virtual internships with individualized mentoring and assessment of engineering thinking. Journal of Biomechanical Engineering, 137, 2, 1-8.

[18] D.W. Shaffer. 2007. How Computer Games Help Children Learn. Palgrave Macmillan, New York.

[19] K. Beckett, \& D.W. Shaffer. 2005. Augmented by reality: The pedagogical praxis of urban planning as a pathway to ecological thinking. Journal of Educational Computing Research, 33, 1, 31-52.

[20] B. Lochner, R.M. Conrad, \& E. Graham. 2015. Secondary teachers' concerns in adopting learning management systems: A US perspective. TechTrends, 59, 5, $62-70$ 